\title{
Moçambique na Rota do Jornalismo de Viagens
}

https://doi.org/10.21814/uminho.ed.48.11

Madalena Oliveira

Centro de Estudos de Comunicação e Sociedade, Instituto de Ciências Sociais, Universidade do Minho, Braga, Portugal https://orcid.org/0000-0001-8866-0000

madalena.oliveira@ics.uminho.pt

\section{Resumo}

A intensificação da circulação de pessoas depois da Revolução Industrial, quer por razões de trabalho quer por motivações de lazer, criou uma espécie de "inquietação geográfica", um interesse generalizado por lugares aparentemente improváveis e uma especial atração por géneros narrativos que cartografam a experiência da viagem. As crónicas e notas de viajantes publicadas pela imprensa especialmente a partir do século XIX eram já um sinal evidente de que a viagem não é apenas a deslocação física entre territórios; é o intercâmbio com outras latitudes afetivas, o confronto com coordenadas sociais e culturais diversas e a expedição que atravessa as fronteiras da identidade. Ir lá e voltar para contar aos outros é, sob todas as formas, a vocação original do jornalismo. No entanto, o seu desenvolvimento profissional e articulação com a segmentação de mercados inspirou a consagração de uma forma especializada de produzir informação de interesse turístico. Apesar de, por vezes, se confundir com finalidades comerciais, o jornalismo especializado em viagens é hoje uma modalidade de jornalismo cultural, menos orientada para a notícia urgente ou para a informação internacional e mais para uma certa construção de representações do mundo que inspirem a descoberta e a exploração de lugares, de gentes, de história e do património. Por razões de proximidade histórica e linguística, pela sua riqueza natural e paisagística e pela sua diversidade cultural, Moçambique também está na rota do jornalismo de viagens de passaporte português. Destino menos frequente que o Brasil, e com atrações eventualmente menos evidentes que as do vasto território brasileiro, o extremo sudeste do continente africano também está no radar dos relatos jornalísticos de viagens. Mas como? Que representações são construídas sobre este país e que atrativos, do ponto de vista da informação, são considerados relevantes? Que imaginário tem, afinal, construído o jornalismo 
de viagens português sobre o território moçambicano? São estas as questões que orientam, neste texto, uma leitura de trabalhos publicados no suplemento Fugas do jornal Público. 0 objetivo é identificar os modos de olhar, os eventuais lugares comuns, as modulações literárias que, caracterizando o jornalismo de viagens em geral, se constituem, no caso particular de Moçambique, como uma narrativa intercultural.

\section{Palavras-chave}

turismo, jornalismo de viagens, destinos, mapas afetivos

\section{A Viagem Como Experiência Cultural}

Por definição corrente, a viagem é o "ato de ir de um lugar até outro, mais ou menos distante" (Porto Editora, n.d., para. 1). Do latim, de viaticu, quererá dizer "provisão para o caminho". Sendo um substantivo comum, é numa só palavra a sugestão de todos os verbos de trânsito - ir, deslocar-se, passar, percorrer, caminhar... Significa tanto o deslocamento em si como o trajeto andado, o que a coloca, em grande medida, no domínio do espaço. Quase todos os sinónimos da palavra viagem - excursão, percurso, itinerário, expedição, jornada - têm, no entanto, uma qualquer alusão à ideia de descoberta ou de suscetibilidade ao perigo, que acrescenta ao ato de ir um sentido inesgotável no propósito de chegar a um qualquer ponto. Há, desde sempre, qualquer coisa de aventuroso em todas as viagens.

Para os povos primitivos, a viagem impunha-se por uma questão de sobrevivência e de segurança. Para procurar proteção e alimento, as comunidades deslocavam-se em busca de condições favoráveis. Pela mudança permanente de lugar, a viagem era, para aquelas sociedades, um modo de vida. Com a fixação progressiva das populações, a viagem passou a justificar-se essencialmente por razões económicas e políticas e pelo interesse da ciência geográfica. A conquista de territórios e as transações comerciais continuaram, durante séculos, a promover a circulação de pessoas, tanto por terra como por mar. A viagem era, com efeito, a condição de comunicação entre pontos separados pela distância, a condição de difusão da própria palavra. Daí que a viagem tenha uma certa intimidade com a difusão do conhecimento, com a evangelização e com a própria ideia de notícia num sentido mais genérico, isto é, tanto com o levar como com o trazer informação. Como lembra Wilbur Schramm (1988), ao contar a história da comunicação humana, "a viagem, assim como as peregrinações dos tempos pré-históricos, deve ter sido uma das primeiras maneiras de passar notícias” (p. 150).

É à industrialização e ao desenvolvimento dos transportes, nomeadamente do caminho de ferro, que se deve a intensificação dos fluxos de pessoas, que começaram efetivamente a viajar muito mais a partir do século XIX. Às trocas mercantis juntou-se o interesse por intercâmbios culturais, uma espécie de "inquietação geográfica" talvez menos intrigada com os limites físicos da superfície terrestre, que moveram gerações de navegadores, por exemplo, e mais atraída pelas formas de ocupação do espaço, pelos hábitos e costumes, enfim, pela diversidade da paisagem humana. 
Os processos de globalização não retiraram o caráter utilitário que as viagens sempre tiveram. A criação de melhores condições para a deslocação, a rapidez e a comodidade dos meios de transporte tornaram a viagem mais frequente por razões de trabalho. Portanto, hoje continua a viajar-se com finalidades económicas e profissionais. No entanto, as motivações para ir de um lugar a outro estão também vinculadas à dimensão de experiência cultural. É verdade que a associação da viagem à ideia de lazer não é inédita do século XX. As deslocações para assistir às Olimpíadas, por exemplo, ou para frequentar estâncias termais já davam conta dessa aproximação na Antiguidade. Mas é definitivamente a partir do último século do milénio que a viagem de ócio se torna uma prática absolutamente regular, programada com orientações cada vez mais vocacionadas para o gozo e a fruição, para a descoberta da diversidade e para fins puramente recreativos.

A propensão para transitar entre lugares atravessa toda a história da humanidade. "Todos os mitos das origens remetem a migrações de povos", anota Henrique Soares Carneiro (2001, p. 232). Foi a viagem a condição do povoamento dos continentes e foi essa também a condição para o encontro entre culturas. Talvez por isso, à palavra viagem sempre se ligaram sentidos que não são exclusivos do movimento físico. A viagem é, em aceção última, a metáfora da própria vida. A vida é uma viagem, diz a expressão popular, num sentido próximo ao que Moisés de Lemos Martins convoca ao falar de travessia e de circum-navegação tecnológica como imagens da experiência cultural contemporânea (Martins, 2015). A viagem é a vivência do espaço, na sua significação mais literal, do que é dado a ver no caminho entre lugares; mas é também a experiência do tempo e das pessoas, dos modos de habitar e de viver. Pelo que reclama dos sentidos, a viagem é uma experiência de interpretação, como sugere José Luís Peixoto (2012) em Dentro do Segredo.

\section{Narrativas de Viagem}

Narrar a viagem é uma prática tão natural quanto o ato de viajar. Para Celia Forneas Fernández (2004), "a conexão entre viajar e narrar a viagem foi sempre muito estreita, tanto que podemos assegurar que todo o viajante é um cronista em potência e que a experiência da viagem não se completa até que seja contada" (p. 223). De acordo com Henrique Soares Carneiro (2001), "a história dos livros de viagens é, de certa forma, a história das próprias viagens, que se perpetuam como relatos” (p. 203). Objetivas ou fantasiosas, as narrativas de viagem serão mesmo anteriores à invenção da escrita. Referindo-se à origem dos fluxos de informação, Wilbur Schramm (1988) sugere que, quando regressavam a casa, os peregrinos e os viajantes "seriam interrogados sobre o que haviam visto" (p. 150). Num texto em que reflete sobre "o múltiplo imaginário das viagens modernas", Henrique Soares Carneiro (2001) explica que "as pessoas nasciam, viviam e morriam no perímetro de poucas dezenas de quilómetros" (p. 203). Por isso, os relatos dos viajantes seriam o único recurso para responder à curiosidade sobre os lugares longínquos.

A literatura documenta em abundância o interesse por este tipo de registos. A própria Bíblia constitui, em várias passagens, um conjunto de narrativas de viagem, seja a 
dos profetas que passavam de lugar em lugar predizendo o futuro, seja a que dá o contexto ao nascimento de Jesus. Com caráter épico, por outro lado, contou Virgílio, em Eneida, no século I a. C., as peripécias da viagem errante de Eneias pelo Mediterrâneo. Em Odisseia, Homero conta o regresso de Odisseu, um herói vagueante que, vitorioso da guerra de Troia, viu cidades e conheceu costumes de muitos homens. E, n' Os Lusíadas, Luís Vaz de Camões narra a epopeia da primeira viagem marítima para a Î́ndia, empreendida pelos portugueses no século XV. Da literatura romântica ou realista portuguesa fazem parte muitos outros exemplos, de que se pode destacar nomeadamente Almeida Garrett, com o seu explícito romance Viagens na Minha Terra, em estilo digressivo. Já em Eça de Queirós, ele próprio um viajante relativamente frequente, a viagem está ora em notas, como em $O$ Egipto. Notas de Viagem (uma coletânea de textos publicados a partir de 1870 no jornal Diário de Notícias), ora no horizonte das suas personagens, como em A Cidade e as Serras, com Jacinto a viajar de Paris para a serra de Tormes, ou em A Capital, a partir da viagem de Artur Corvelo de Oliveira de Azeméis para Lisboa.

A partir do século XIX, os jornais também intensificariam a publicação de crónicas e notas de viagens. Tratava-se, na generalidade, de apontamentos pessoais de "intelectuais" que, em escritos de género híbrido, entre o relato descritivo-jornalístico e o relato literário, falavam das cidades que iam conhecendo ou da dinâmica cultural que aí iam experimentando. Havia, com efeito, um especial interesse por aquilo que vinha do estrangeiro, que trazia os "ares da modernidade" e promovia o debate nos principais círculos de discussão, como as tertúlias literárias ou mesmo os cafés. Desde o século XVIII que já se viajava "para se instruir sobre relações do homem com os seus próximos, se ilustrar sobre a vida do homem, estudar objetivamente modelos de organização social e política dos países estrangeiros para aprender a solucionar os problemas próprios" (Forneas Fernández, 2004, p. 222).

Com o aparecimento da fotografia, a viagem passaria a contar-se também visualmente e no impulso de um bilhete-postal. Muito prestável aos apontamentos de viagem e apropriado à imagem excursionista (Martins \& Oliveira, 2011), o postal ilustrado era ágil e gracioso, dava a ver num sentido mais literal os lugares visitados. Fazia da viagem uma experiência mais partilhada, já muito próxima do atual gesto de registar imagens com o telemóvel e de as enviar no instante de uma rápida mensagem ou publicação nas redes sociais. 0 apelo da imagem desses lugares de viagem inspirou também a criação de revistas especializadas e a publicação de livros com elevado recurso a ilustrações, de que é emblemática, no contexto português, por exemplo, toda a obra literária do escritor-viajante Gonçalo Cadilhe, que viaja para escrever, como faziam já no século XIX os “viajantes profissionais”. Como explica Celia Forneas Fernández (2004), esses viajantes eram "geralmente escritores de fama reconhecida, que se deslocavam até aos lugares que atraíam com um magnetismo especial o interesse dos leitores" (p. 222). 


\section{Jornalismo de Viagens}

A origem do jornalismo está, de algum modo, associada à viagem e às notícias que chegavam de pontos distantes. Eram esses relatos que passavam de boca em boca e que, progressivamente, se registavam nas primeiras folhas noticiosas. Há no jornalismo de viagens, hoje, ainda alguns traços deste princípio. 0 jornalista vai e traz "o que contar". Com uma finalidade muito vocacionada para o turismo, esta modalidade do jornalismo é menos orientada para as preocupações com as relações comerciais ou as questões de geopolítica. Para Ben Cooking (2009), "o jornalismo de viagens tem sido tradicionalmente percebido como tendo um estatuto e um nível de importância muito inferior ao das 'hard' news da política e dos assuntos internacionais" ( $p$. 55). Com efeito, o jornalista que narra viagens e apresenta destinos faz notícia das gentes, das paisagens, da gastronomia, das atividades que descrevem o quotidiano. Falando dos lugares e dos seus pontos de interesse, assinala a história e, por vezes, também as idiossincrasias políticas e culturais, ainda que apenas com o pretexto de fazer o enquadramento dos lugares e não tanto com a preocupação de dar conta dos acontecimentos específicos. 0 jornalismo especializado em viagens é hoje uma modalidade de jornalismo cultural, de facto, menos orientada para a notícia urgente ou para a informação internacional e mais para uma certa construção de representações do mundo que inspirem a descoberta e a exploração de lugares, de gentes, de história e do património.

Procurando desenvolver um género narrativo atraente, próximo da literatura, o jornalista que produz estas narrativas baseia-se na experiência pessoal, num relato mais subjetivo e condizente com a liberdade do escritor. É pelo recurso a uma linguagem extraordinariamente adjetivada que, para alguns autores, o jornalismo de viagens "parece estar em contradição com os principais valores do jornalismo - a objetividade, a independência editorial e a relevância pública” (Fursich, 2002, p. 61). Num texto publicado na revista Estudos de Comunicação, Karine Wenzel e Valquíria Michela John (2012) chegam mesmo a sugerir alguma dificuldade em diferenciar o texto de algumas revistas de "um panfleto de agência de turismo" (p. 303).

Correspondendo a uma lógica de especialização da imprensa, em resposta a interesses cada vez mais segmentados, o jornalismo de viagens constitui um modelo de negócio muito específico, por vezes, em associação com empresas ou instituições do setor do turismo. Não raras vezes, os jornalistas viajam a convite de agências de viagens ou promotores turísticos, para destinos definidos, portanto, por meio de patrocinadores. A questão do financiamento é, na verdade, um dos pontos críticos desta atividade. Reconhecendo que "muitas formas de jornalismo de viagens incluem reportagens publicitárias e artigos patrocinados", Ben Cooking (2009) entende que este facto "mancha a questão da objetividade e dá sustento à perceção de que ao jornalismo de viagens falta a distância crítica associada a outros géneros, como os do jornalismo político e financeiro" (p. 56).

Com características muito particulares, quando comparadas à prática jornalística convencional, o jornalismo de viagens também se orienta por critérios de noticiabilidade, 
por vezes, distintos. Sendo verdade que a procura dos destinos de que se fala pode ser enquadrada por valores-notícia padrão (como o lugar menos poluído, o lugar mais visitado, um novo destino turístico, o lugar mais quente, o destino que gerou mais receita...), em princípio, não é o imperativo da "última hora" o que determina a "marcação da viagem". Tão-pouco a proximidade de um acontecimento. No plano das viagens e do interesse cultural dos lugares, pode mesmo ser a distância um critério de seleção dos destinos sobre os quais produzir matéria. Por outro lado, o conceito de atualidade é aqui, normalmente, relativizado, considerado num horizonte mais estendido no tempo.

Próximo do que Megan Le Masurier (2015) descreve como sendo o slow journalism - "um jornalismo long-form baseado na qualidade, que significa pesquisa em profundidade, explanação, contexto, com narrativas mais longas bem trabalhadas" (p.142)-, o jornalismo de viagens é, essencialmente, um jornalismo de experiências. Embora possa assentar em factos, tem um interesse particular pelas sensações e pelas experiências individuais. É por isso que, ao contrário da narrativa jornalística padrão, the convém a descrição detalhada, rica em adjetivos, sedutora e cativante.

$\mathrm{Na}$ imprensa como na televisão, privilegia-se o caricato, o extraordinário, o singular. Dá-se voz às fontes populares, explora-se a descrição e a interpretação. A crónica de viagem pode seguir a ordem cronológica do itinerário, estar dividida em capítulos ou incluir recomendações para outros viajantes. 0 prisma é o do jornalista, menos obrigado às normas do contraditório. É, aliás, "frequente que o viajante narrador se converta num dos fios condutores do relato, o que está favorecido pela marcada predileção da crónica de viagem por um relato na primeira pessoa" (Forneas Fernández, 2004, p. 226).

Criativo, como sugere Mariano Belenguer Jane (1992), o jornalismo de viagens constrói imaginários e cria sonhos, ao mesmo tempo que produz perceções culturais. Representando uma evolução dos primeiros relatos conhecidos para formas mais sofisticadas de expressão, tem inclusive um sentido prescritivo (Palau Sampio \& Lekant, 2017). Sugere estilos de vida, no mesmo ato em que dá a conhecer outras comunidades e as suas manifestações culturais. Desse ponto de vista, o jornalismo de viagens tem mesmo um caráter de revelação sobre a diversidade humana, sobre o "outro". Nessa atividade de divulgação, que constitui uma espécie de desocultação, a narrativa jornalística inspira aquilo que João Sarmento (2018) define como o ato de "colecionar lugares".

Serão, na realidade, "colecionadores de destinos e territórios" os autores de blogues especializados - como o português Alma Viajante (https://www.almadeviajante.com) - que expandem a função do jornalismo de viagens para o domínio de uma certa informalidade, uma espécie de "jornalismo participativo ou do cidadão". Para Bryan Pirolli (2015), "definir hoje o jornalismo de viagens é uma tarefa difícil graças à pletora de escritos de viagem que se podem encontrar na web, em livros, em programas de televisão, vídeos do YouTube e aplicações de smartphone" (pp. 104-105). Ainda assim, é na mistura de informação - mais séria ou mais ligeira - com perspetivas 
críticas que estes escritos - jornalísticos ou protojornalísticos - que podem ter um papel relevante como interfaces de interculturalidade.

\section{Moçambique, Território de Afetos}

Em Portugal, há vários espaços mediáticos dedicados ao jornalismo de viagens. Com a exceção da rádio, menos dada a esta especialização da atividade jornalística certamente pela ausência de imagens que caracteriza por natureza este meio, tanto a televisão como a imprensa especializada procuram cobrir este segmento de mercado. Dedicam-se ora ao destaque de exemplos excecionais de hotelaria ora ao exótico que pode haver nos sabores de gastronomias do mundo. Exploram a experiência pessoal, as impressões singulares que os lugares deixam nas pessoas e as representações visuais que é possível fixar no enquadramento de uma câmara fotográfica ou de um vídeo. Fazem sugestões de férias, de expedições de descoberta ou de aventuras excecionais por mapas que misturam o banal, o simples e o quotidiano com o excêntrico, o ímpar e o exclusivo. Oferecendo a visão "virgem" de quem vai pela primeira vez, completa-se por vezes com a orientação de quem escolheu esses lugares para se fixar como imigrante, como propõe o Portugueses Pelo Mundo, o formato da RTP que "mistura um programa documental com um programa de viagens" e escolhe aqueles que "têm bem enraizada a identidade de origem [a portuguesa], mas não impõem limites à incorporação de novos hábitos” (Rádio e Televisão de Portugal, n.d., paras. $5-8)$.

Neste texto, fixamo-nos em Moçambique como destino. Na rota de alguns dos mais influentes bloggers portugueses de viagens, como o Dobrar Fronteiras (https://dobrarfronteiras.com), o Tempo de Viajar (https://www.tempodeviajar.com) ou o Alma de Viajante (https://www.almadeviajante.com), este país do sudeste africano também é indicado na bússola de periódicos impressos. Em junho de 2016, a revista Volta ao Mundo apontava para "Maputo: De Coração Aberto e Com Sabor a África", numa reportagem onde se lia: "o oceano Índico, o sorriso das crianças, a omnipresença da música... tudo isto é Maputo, tudo é África” (Oliveira, 2016). Em novembro de 2019, numa outra edição, fazia-se uma "Viagem Vibrante Pela Itha Onde Tudo Começou" (Sérgio, 2019). É, porém, no suplemento Fugas editado pelo jornal Público que assentamos uma leitura mais sistemática. Sem a pretensão de uma análise de conteúdo em profundidade, lemos neste artigo recortes desta publicação, em busca de sinais que permitam identificar as representações construídas deste país, bem como as atrações destacadas. Procuramos também compreender que imaginário se constrói sobre este território com laços históricos a Portugal.

Com menções a registos avulsos de edições publicadas a partir de 2010, examinamos exaustivamente as referências a Moçambique dos suplementos produzidos entre janeiro de 2016 e dezembro de 2020, num total de 260 edições. Facilitada pela pesquisa eletrónica pela palavra "Moçambique”, a identificação de matérias centradas na paisagem, natural e/ou humana, daquela que é conhecida, na imprensa da especialidade, como "a terra dos sorrisos" dá conta de um país que, na comparação 
com outras nações de expressão portuguesa, tem sido consideravelmente menos visível do que o Brasil, por exemplo.

Entre 2010 e 2015, Moçambique teve chamada de capa do suplemento Fugas duas vezes (edições de 9 de junho de 2012 e de 9 de março de 2013). No entanto, entre 2016 e 2020 , tendo sido o foco de dois trabalhos extensos, nunca foi eleito como destino de primeira página, ao contrário de outras paragens de acento lusófono. De Angola fez-se capa em março de 2020 , com uma proposta para "uma lenta viagem de comboio ao interior profundo". Guiné-Bissau foi o cenário de "uma história com sabor a saudade", em setembro de 2017. 0 território de São Tomé e Príncipe, por seu lado, foi realçado em capa três vezes: em janeiro de 2016, numa alusão à experiência do tempo "devagar-devagar"; em abril de 2017, num trabalho focado nos sabores da gastronomia provada como "livro de história"; e em junho de 2019, a propósito de lições e histórias de uma semana na ilha de São Tomé. Já do Brasil, no período em apreciação, para além de outros destaques do interior do suplemento, assinalam-se quatro capas: em abril de 2016, com um mergulho na floresta Amazónia, em junho do mesmo ano, num "retrato doce e salgado" de Pernambuco, em dezembro de 2018, numa redescoberta gastronómica de produtos nativos, e, em agosto de 2019, numa exploração dos “kalunga de Goiás".

Sem a exibição de montra que pode representar a página de entrada numa publicação impressa, Moçambique não escapa, no entanto, à letra deste jornalismo itinerante na segunda década do milénio. 0 retrato do país visto de fora nas páginas da edição do Fugas revela uma tendência para inscrever esta região da costa do Índico numa certa nostalgia em relação a África. Como outros países do continente africano, há nos relatos destas narrativas um tipo de sabor a África que se procura transmitir, uma espécie de continente perdido da memória dos portugueses. É, na verdade, uma forma de falar de África que não tem equivalente para a Europa, normalmente exibida pelas suas grandes cidades e menos pelo cheiro da terra, por exemplo. Assim se mostra a capital na edição de 20 de fevereiro de 2016: "em Maputo, sentimos África e o seu caos", “em Maputo respira-se África” (Fugas, 20 de fevereiro de 2016).

Dessa matriz africana intui-se um traço místico inescapável, uma espécie de marca genética que Moçambique partilha com outras paragens históricas dos portugueses no tempo das colónias. Mas salienta-se também uma quase inescapável condenação à desorganização. Em março de 2013, num texto sobre o ontem e o hoje da antiga Lourenço Marques, os problemas do urbanismo contrastam com essa autenticidade que descreve África: "cidade de avenidas, praças, jardins, prédios, parques, Maputo debate-se com sobrelotação, trânsito caótico, deficiente recolha de lixo. Cercam-na bairros de ruas irregulares ladeadas por casas com paredes de madeira ou adobe e cobertura de capim ou zinco" (Fugas, 9 de março de 2013). Imagem semelhante descrevia, em fevereiro de 2016, a jornalista Soraia Amaro referindo-se ao "avanço do betão e um trânsito desorganizado" e reconhecendo que "há uma desorganização aparente que pode ser desesperante para quem chega, mas depressa nos apercebemos de que há lógica dentro do caos" (Fugas, 6 de fevereiro de 2016). 
Embora não seja propriamente um destino de praia preferencialmente eleito pelos circuitos comerciais das agências europeias, a fotografia de Moçambique descreve-se igualmente pela localização costeira. Na edição de dezembro de 2011, era assim que se apresentava o país: "a Barra é uma minúscula amostra das potencialidades do país enquanto destino turístico: um imenso areal estendido entre o oceano e uma vasta área de mangal, que proporciona a qualquer banhista que se preze os prazeres da praia e de uma natureza muito tropical" (Fugas, 10 de dezembro de 2011). Do mesmo modo, em fevereiro de 2016, reconhecia-se que "não é difícil encontrar praias paradisíacas", embora distantes da capital, com o Índico a mostrar-se "difícil de conquistar" (Fugas, 20 de fevereiro de 2016), ainda que horizonte para onde se avista também um "pôr-do-sol mágico" (Fugas, 7 de outubro de 2017), "estonteante, numa explosão de cores rápida e intensa”, como dizia uma leitora, na edição de 9 de julho de 2016.

No que diz respeito aos lugares, destacam-se nos percursos pela cidade de Maputo, especialmente os seguintes aspetos: Malafaia, lugar histórico da nacionalidade moçambicana, a Praça da Independência, que "continua hoje na sua dinâmica monumental de outrora" (Sousa, 2019, p. 259) dominada pela estátua de Samora Machel, "à maneira soviética", a estação de Caminho de Ferro, descrita como uma das mais bonitas de África, a Feira de Artesanato, Gastronomia e Flores, o Mercado Central. Não obstante o caos urbano, é a abundância de verde que, por outro lado, se sinaliza nos detalhes identificados por quem visita a cidade: "acácias vermelhas e amarelas enchem as ruas de cor, e os frangipanis floridos são uma visão especial, que nos faz agradecer o privilégio de assistir" (Fugas, 6 de fevereiro de 2016).

Do resto do país, destacam-se entre 2010 e 2020 outras localizações: a Ilha de Matemo - Parque Nacional dos Quirimbos, o parque natural da Gorongoza, a Beira ou a Zambézia, a segunda maior província moçambicana, "pródiga província", escreve-se no Fugas, que "guarda um bom punhado de histórias e um imenso potencial de atração para viajantes que procuram itinerários além das rotas batidas". Descrita como um lugar onde os viajantes se movem "por esses nadas que não têm lugar nos roteiros turísticos mas que estão lá, nos lugares de acaso da viagem, como uma seiva invisível a lubrificar o mecanismo da vida" (Fugas, 7 de outubro de 2017), Zambézia é também a porta para o país real que "vai mais devagar".

Sobre as pessoas, diz-se que são sempre sorridentes, dando uma ideia de acolhimento. É quase sempre assim, numa expressão ingénua e feliz, que os moçambicanos fazem o retrato humano do jornalismo de viagens. Reconhecidos como "mestres na arte de improvisar respostas, reutilizar objetos e arranjar soluções para os (muitos) problemas do dia a dia" (Fugas, 6 de fevereiro de 2016), os habitantes nativos são o rosto do "Moçambique das minorias felizes", do povo que, em Zambézia, por exemplo, faz da bicicleta "o transporte público e privado por excelência" (Fugas, 7 de outubro de 2017).

Uma das condições mais destacadas de Moçambique é a relação com Portugal. Faz-se referências ao antigo nome de Maputo como a Lourenço Marques do tempo dos portugueses, bem como alusões históricas que remetem de algum modo a Portugal, como esta: "o litoral africano do Índico teve um papel importantíssimo na expansão 
marítima portuguesa" (Fugas, 7 de outubro de 2017). Ou esta em que, se identificando Maputo com África, se avisa que aí "também sentimos Portugal, embrenhado nas ruas, na língua, nos costumes" (Fugas, 20 de fevereiro de 2016). Outra referência que cruza necessariamente com Portugal tem a ver com a gastronomia e a identificação de restaurantes de origem portuguesa: "em vários pontos da cidade, restaurantes portugueses testemunham uma ligação que permanece, apesar do tempo" (Fugas, 9 de março de 2013). Em 2016, é a mesma alusão aos ambientes de Portugal que encontramos: "no restaurante Pizza House, na Avenida Mao Tse Tung, mesmo junto ao edifício que alberga a Embaixada portuguesa, o ambiente é o mesmo de qualquer café em Portugal" (Fugas, 20 de fevereiro de 2016).

Nas notas itinerantes que podemos registar da leitura das matérias publicadas no Fugas, poderíamos dizer que se destacam as paisagens naturais (a fauna, a flora, o mar...), as pessoas e as manifestações culturais (o artesanato, a arte acessível que enche as ruas da capital, a música, a literatura...), a economia informal, a vida da cidade (os cafés, os restaurantes, os monumentos...), os restos da memória colonial e a familiaridade da língua portuguesa (embora sem menções que remetam para a ideia de lusofonia). No país onde, "a sul, tudo de novo", "tão depressa se está numa praia do Índico a mergulhar num recife de coral como se caminha pela savana rasteira ali bem perto" (Fugas, 15 de fevereiro de 2014).

Do lugar de onde se diz que também é o mais saboroso caju do mundo (Miguel Esteves Cardoso, Fugas, 22 de dezembro de 2018), o jornalismo de viagens do suplemento do Público mapeia os traços da geografia física, mas também as texturas do humano. Ainda que se possa dizer que Moçambique é, "em si mesmo, uma memória da colonização" (Sousa, 2019, p. 263), no tom de deslumbramento que caracteriza estas narrativas, o imaginário deste vasto território onde o português é a única língua oficial, é o de um território que se visita pelos afetos.

\section{Agradecimentos}

Este trabalho é financiado por fundos nacionais através da FCT - Fundação para a Ciência e a Tecnologia, I.P., no âmbito do projeto UIDB/00736/2020.

\section{Referências}

Belenguer Jane, M. (1992). La prensa especializada en viajes: La aventura de um periodismo creativo. In A. Antona Illanes, M. Belenguer, C. Carreras, M. C. Fernandez, J. M. Gomez y Mendez, F. Perales, M. Ponce, R. Reig, M. J. Ruiz, \& E. Sanchez(Eds.), Lenguaje informativo y filmográfico (pp. 19-26). Universidad de Sevilla.

Carneiro, H. S. (2001). 0 múltiplo imaginário das viagens modernas: Ciência, literatura e turismo. História: Questões \& Debates, 35, 227-247. https://doi.org/10.5380/his.v35i0.2681

Cooking, B. (2009). Travel journalism. Journalism Studies, 10(1), 54-58. https://doi. org/10.1080/14616700802560500

Forneas Fernández, M. C. (2004). Periodismo o literatura de viajes? Estudios sobre el Mensaje Periodístico, 10, 221-240. https://revistas.ucm.es/index.php/ESMP/article/view/ESMP0404110221A 
Fursich, E. (2002). How can global journalism represent the 'other'? A critical assessment. Journalism, 3, 57-88. https://doi.org/10.1177/146488490200300102

Martins, M. L. (2015). Lusofonias - Reinvenção de comunidades e combate linguístico-cultural. In M. L. Martins (Eds.), Lusofonia e interculturalidade - Promessa e travessia (pp. 7-24). Húmus.

Martins, M. L., \& Oliveira, M. (2011). Postal a postal. In M. L. Martins, \& M. Oliviera (Eds.), Portugal ilustrado em postais (pp. 1-22). CECS.

Masurier, M. L. (2015). What is slow journalism? Journalism Practice, 9(2), 138-152. https://doi.org/10.10 80/17512786.2014.916471

Oliveira, J. F. (2016, 23 de junho). Maputo: de coração aberto e com sabor a África. Volta ao Mundo. https:// www.voltaaomundo.pt/2016/06/23/maputo-de-coracao-aberto-e-com-sabor-a-africa1/destinos/12803/

Palau Sampio, D., \& Lekant, M. (2017). Periodismo de viajes e innovación en la red. Perfiles, apuesta y motivación de los bloggers. Zer. Revista de Estudios de Comunicación, 22(43), 167-184. https://doi. org/10.1387/zer.17938

Peixoto, J. L. (2012). Dentro do segredo. Uma viagem na Coreia do Norte. Quetzal Editores.

Pirolli, B. (2015). Travel journalism 2.0. Tourist's motivations, expectations, and practices online. Sur le Journalisme, About Journalism, Sobre o Jornalismo, 4(2), 102-115.

Porto Editora. (n.d.). Infopédia. Retirado a 20 de setembro, 2021, de https://www.infopedia.pt/dicionarios/lingua-portuguesa/viagem

Rádio e Televisão de Portugal. (n.d.). Portugueses pelo mundo. https://www.rtp.pt/programa/tv/ p26498\#

Sarmento, J. (2018). Colecionar países e territórios: Uma proposta de contabilização de lugares visitados. Revista Luófona de Estudos Culturais, 5(2), 317-331. https://doi.org/10.21814/rlec.335

Schramm, W. (1988). The story of human communication. Cave printing to microchip. Harper \& Row Publishers.

Sérgio, J. (2019, 28 de novembro). Moçambique: viagem vibrante pela ilha onde tudo começou. Volta ao Mundo. https://www.voltaaomundo.pt/2019/11/28/mocambique-viagem-vibrante-pela-ilha-onde-tudo-comecou-b/destinos/584076/

Sousa, V.(2019). A memória como promotora de interculturalidade em Maputo, através da preservação da estatuária colonial. Comunicação e Sociedade, 249-267. https://doi.org/10.17231/comsoc.0(2019).3072

Wenzel, K., \& John, V. M. (2012). Jornalismo de viagens: Análise das principais revistas brasileiras. Estudos de Comunicação, 11, 291-311. http://ec.ubi.pt/ec/11/pdf/EC11-2012Mai-14.pdf 